Research Paper

\title{
Efficacy and Safety of Everolimus plus Somatostatin Analogues in Patients with Neuroendocrine Tumors
}

\author{
Wenhao Ge¹, Dongkai Zhou ${ }^{3}$, Lijun Zhu¹, Wei Song1, Weilin Wang $1,2,3 \bowtie$ \\ 1. Key Laboratory of Precision Diagnosis and Treatment for Hepatobiliary and Pancreatic Tumor of Zhejiang Province, Hangzhou 310003, Zhejiang, China \\ 2. State Key Laboratory \& Collaborative Innovation Center for Diagnosis and Treatment of Infectious Diseases, Zhejiang University, Hangzhou 310003, \\ Zhejiang, China \\ 3. Division of Hepatobiliary and Pancreatic Surgery, First Affiliated Hospital, School of Medicine, Zhejiang University, Hangzhou 310003, Zhejiang, China
}

$\square$ Corresponding author: Weilin Wang, MD, Ph.D. Key Laboratory of Precision Diagnosis and Treatment for Hepatobiliary and Pancreatic Tumor of Zhejiang Province, Division of Hepatobiliary and Pancreatic Surgery, First Affiliated Hospital, Zhejiang University School of Medicine, \#79 Qingchun Road, Hangzhou, Zhejiang Province, China. E-mail addresses: wam@zju.edu.cn

(c) Ivyspring International Publisher. This is an open access article distributed under the terms of the Creative Commons Attribution (CC BY-NC) license (https://creativecommons.org/licenses/by-nc/4.0/). See http://ivyspring.com/terms for full terms and conditions.

Received: 2018.03.06; Accepted: 2018.09.10; Published: 2018.12.10

\begin{abstract}
Everolimus, an oral mammalian target of rapamycin(mTOR) inhibitor, which acts upstream of the phosphoinositide 3-kinase/protein kinase B(PI3K/AKT) signaling pathway to downregulate cellular metabolism, growth, proliferation, and angiogenesis, has been shown to significantly prolong the progression-free survival of patients with advanced neuroendocrine tumors. Somatostatin analogues (SSAs) such as octreotide, lanreotide, and pasireotide, have been widely used for symptom control and antiproliferative effects in metastatic or unresectable neuroendocrine tumors. Both everolimus and SSAs have demonstrated antitumor effects in randomized controlled trials (RCTs) involving selected patients with neuroendocrine tumors, but the efficacy and safety of their combined use require further investigation. In this systematic review, we summarize the published studies that have investigated the use of everolimus and SSAs to provide a comprehensive understanding of their combined effects and better guidance for the treatment of neuroendocrine tumors.
\end{abstract}

Key words: everolimus, neuroendocrine tumors, somatostatin analogues, safety, efficacy

\section{Introduction}

Neuroendocrine tumors (NETs) are heterogeneous tumors with various biological behaviors and clinical outcomes. Over the past two decades, the incidence of NETs has increased dramatically worldwide [1, 2]. NETs usually originate from the gastrointestinal tract, lung, thyroid, pancreas, and other parts of the body where somatostatin receptor (SSTR) subtypes 1-5 have been shown to be widely distributed, especially the small intestine and pancreas $[3,4]$. The majority of SSTR-positive tumors simultaneously express multiple SSTR subtypes, with one or more exhibiting dominance; for example, SSTR subtype 2 predominance is generally found in pancreatic NETs and carcinoid tumors $[5,6]$. Thus, somatostatin and its analogues have emerged as a potential treatment modality for SSTR-positive tumors. Since the first use of somatostatin in a patient with carcinoid syndrome in the 1970s [7], somatostatin analogues (SSAs), primarily octreotide and lanreotide, have been shown to be effective in slowing the growth of tumors and controlling the symptoms of carcinoid syndrome, as evaluated in the CLARINET and PROMID studies [8, 9], however, due to the limited cases and short observation time, these two studies did not confirm their role in improving overall survival and anti-tumor effect, whereas to our surprise, in the long-time survival results of PROMID study, overall survival was similar between octreotide and placebo subgroups[10]. Thus, previous results might suggest that the anti-tumor effects of SSAs require further discussion, and combined therapy with other treatment, especially popular targeted 
therapy and immunotherapy, might be more effective.

More and more tumor types are showing associations with genetic mutations; thus, gene and molecular targeted therapies may provide promising treatment options for tumors [11, 12]. For example, somatic mutations, including MEN, VHL, and the newly reported MUTYH, CHEK2, and BRCA2 mutations, occur in approximately $17 \%$ of pancreatic NETs, one of the main pathways involved is mTOR signaling [13]. Everolimus, an oral mTOR inhibitor [14], is one of the most commonly used targeted therapies, and it has demonstrated significantly improved progression-free survival(PFS) rates in several clinical trials on NETs, particularly the RADIANT series [15-17].

NETs are usually found in cases with a high tumor burden or metastatic status [1]. Because of the limited success of surgical resection and traditional cytotoxic chemotherapy, molecular targeted therapies, such as everolimus, sunitinib, and bevacizumab, have received increasing attention in recent years [18, 19]. Given that resistance is likely to develop with single-agent regimens, while combination therapies may elicit more favorable outcomes, clinical trials evaluating octreotide in combination with everolimus, pazopanib, or bevacizumab $[15,20,21]$, or octreotide plus bevacizumab compared with octreotide plus interferon $\alpha-2 b$ [22], are underway.

As the most commonly used molecular targeted therapy for symptom control, SSAs and everolimus both display favorable outcomes in patients with NETs, whereas the efficacy and safety of their use in combination are still uncertain. This systematic review summarizes the published studies that have investigated the use of everolimus plus SSAs to provide a comprehensive understanding of their combined effects and better guidance for the treatment of NETs.

\section{Methods}

\section{Inclusion and exclusion criteria}

We conducted an extensive literature search of all randomized controlled trials (RCTs) and prospective and retrospective studies that enrolled adult patients ( $\geq 18$ years of age) with pathologically confirmed NETs, including lung, thymus, or gastroenteropancreatic primary tumors, carcinoid tumors, and those of uncertain origin, with an Eastern Cooperative Oncology Group performance status score of $0-2$.

Eligible studies included patients treated with SSAs (primarily octreotide, lanreotide, or pasireotide) in combination with the mTOR inhibitor everolimus, with or without comparative subgroups such as SSAs alone or everolimus alone. Patients who received prior interventions or treatments before they were included in relevant studies were also eligible, and discussed below. Phase I studies, retrospective studies that included less than 30 patients, and case reports were excluded.

\section{Search strategies and identification of studies}

We searched the Pubmed, Embase, Cochrane Library, and Clinical Trials databases for published studies, dated prior to July 15, 2018. The search consisted of three parts, neuroendocrine tumors parts comprised neuroendocrine tumor(s), tumour(s), neoplasm(s) or carcinoid tumor, SSAs parts comprised somatostatin analogues, octreotide, lanreotide or pasireotide, everolimus parts comprised mTOR inhibitor, everolimus or RAD001. The search was independently conducted by two researchers and discussed whether they met inclusion and exclusion criteria.

\section{Data extraction}

Efficacy data, including survival data (with or without 95\% confidence intervals) (i.e., median progression-free survival [PFS] and overall survival [OS]) and response rates (i.e., complete response [CR], partial response $[\mathrm{PR}]$, stable disease [SD], progressive disease $[\mathrm{PD}]$, objective response rate [ORR; $\mathrm{CR}+\mathrm{PR}]$, and disease control rate [DCR; $\mathrm{CR}+\mathrm{PR}+\mathrm{SD}$ ] rates), were evaluated according to the Response Evaluation Criteria In Solid Tumors (RECIST version 1.0) [23]. Not all studies presented detailed survival data, some survival data may not have been evaluable until the trial endpoint, and some studies listed the proportion of progression-free cases at 9 or 12 months, for example. If available, data on elevated biomarkers such as chromogranin A (CGA), neuron-specific enolase (NSE), and 5-hydroxyindoleacetic acid (5-HIAA) were also evaluated.

Safety measures included treatment discontinuation for any reason, primarily disease progression, serious adverse events (AEs), and withdrawal of consent. AEs were classified in accordance with the National Cancer Institute's Common Terminology Criteria for Adverse Events version 3.0.

\section{Quality assessment}

Study qualities were assessed by two reviewers independently using Cochrane criteria for RCTs[24], the Newcastle-Ottawa scale(NOS) was used to assess comparative non-RCTs or non-comparative studies [25], disagreements were reconciled by discussion and reached final agreements. 


\section{Results}

\section{Study selection}

A total of 3420 studies were identified from the literature search, after duplicate articles confirmed, we primarily evaluated the results through titles and abstracts screening, then full-text articles were assessed, eventually eight articles were deemed eligible and included in this systematic review. The study flow was summarized in the diagram Figure 1.

\section{Study characteristics and quality}

The eight studies on the combination of SSAs and everolimus for the treatment of NETs comprised four comparative studies, including three RCTs, one randomized double-blind placebo-controlled phase III study [15, 26], two randomized open-label phase II studies [27, 28], and one non-randomized open-label phase II study [29], the other four non-comparative studies include three prospective phase II studies [30-32], and one retrospective cross-sectional analysis [33]. The comparative studies evaluated everolimus in combination with SSAs versus everolimus or SSAs alone, and the most commonly used SSAs were octreotide and pasireotide long-acting repeatable (LAR).

The study details, summarized in Table 1, include the study reference, location, type, number of patients included, treatment details (drug dose and regimen, and mode of administration), and treatment outcomes (primarily efficacy and safety data such as survival time/rate, treatment response, and AEs).

Of the three RCTs, the randomization of the double-blind designed RADIANT-2 study and open-label LUNA study were conducted by interactive voice response systems with low risk of bias, the other open-label designed COOPERATE-2 did not mention the randomization, all the RCTs presented reasonable control program and complete endpoint data including efficacy and safety data. The comparative non-randomized open-label study and all the four non-comparative studies achieved 7 points or higher according to NOS. There might be variations between the RCTs and non-comparative studies, as it was unsuitable to conduct meta-analysis to compare the efficacy and safety of included studies, extracted results were summarized qualitatively.

\section{Efficacy}

Survival and tumor response data are summarized in Table 2. Seven of the eight studies reached the median PFS, ranging from 11.8-25.8 months, the RADIANT-2 study, a subgroup of the RADIANT study (everolimus single-arm treatment) and the retrospective study reached the median OS of 29.2, 35.2, 24.9 and 26.4 months, respectively. Regrettably, most patients did not reach the median OS, and a considerable proportion of patients discontinued the proposed treatment due to disease progression or serious AEs. Although it was not feasible to conduct quantitative comparisons and analyses to evaluate statistical differences among these limited studies, there were trends suggesting that the combination of everolimus and SSAs resulted in greater survival time compared with the single-arm therapies, especially SSAs alone (16.7 vs. 9.7 months, Yao et al. 2010; 16.4 vs. 11.3 months, Yao et al. 2011; 11.8 vs. 8.5 months, Ferolla et al. 2017).

In the 2008 phase II study by Yao et al., the median PFS was 7 months longer in the combination treatment group than in the everolimus single-arm group, and in the RADIANT-2 study, the median PFS was 5.1 months longer in the combination treatment group than in the SSA single-arm group. In contrast, in the COOPERATE-2 and LUNA studies, no significant differences were found between these groups. In the final OS analysis of the RADIANT-2 study, no significant differences were found between the everolimus plus octreotide LAR and the placebo plus octreotide LAR groups (median OS, 29.2 vs. 35.2 months, respectively; HR, 1.17; 95\% CI, 0.92-1.49), whereas, the addition of everolimus significantly increased the incidence of adverse events [26]. Due to the relatively short study time, and some of the patients suffered disease progression turned to other treatment, it is still difficulty to explain whether adding everolimus to SSAs could prolong OS over SSA single-arm treatment.

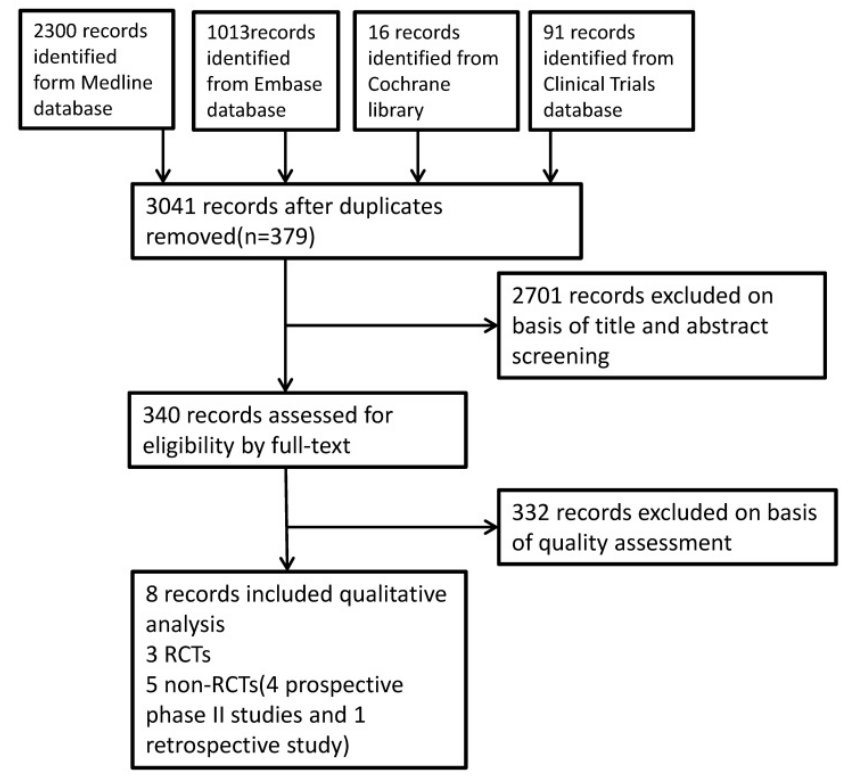

Figure 1. Study flow diagram 
Table 1. Characteristics of the studies included in this review.

\begin{tabular}{|c|c|c|c|c|c|}
\hline Study reference & Study location & $\begin{array}{l}\text { No. of } \\
\text { patients }\end{array}$ & Study population & Treatment, dose, and duration* & Outcomes \\
\hline $\begin{array}{l}\text { Non-comparative study }(n=4) \\
\text { Yao et al. 2008, phase II study }\end{array}$ & USA & 60 & $\begin{array}{l}\text { Metastatic or unresectable } \\
\text { locoregional NETs }\end{array}$ & $\begin{array}{l}\text { Octreotide, Everolimus } 5 \mathrm{mg} / \text { day } \\
(\mathrm{n}=30) \text { vs. } 10 \mathrm{mg} / \text { day }(\mathrm{n}=30), \\
48 \text { weeks }\end{array}$ & $\begin{array}{l}\text { PFS, OS, PR, SD, } \\
\text { PD, Safety }\end{array}$ \\
\hline Bajetta et al. 2014, phase II study & $\begin{array}{l}\text { Italy, multicenter } \\
\text { study }\end{array}$ & 50 & $\begin{array}{l}\text { Metastatic or locally } \\
\text { advanced NETs }\end{array}$ & $\begin{array}{l}\text { Everolimus plus octreotide, } 519 \\
\text { days (median) }\end{array}$ & $\begin{array}{l}\text { TTP, OS, ORR, } \\
\text { Safety }\end{array}$ \\
\hline $\begin{array}{l}\text { Capdevila et al. 2015, retrospective } \\
\text { cross-sectional analysis }\end{array}$ & $\begin{array}{l}\text { Spain, multicenter } \\
\text { study }\end{array}$ & $\begin{array}{l}57 \\
\text { (everolimus } \\
\text { subgroup) }\end{array}$ & NETs & $\begin{array}{l}\text { Everolimus plus lanreotide, } 5.1 \\
\text { months (median) }\end{array}$ & $\begin{array}{l}\text { TTP, OS, CR, } \\
\text { PR, SD, PD, } \\
\text { Safety }\end{array}$ \\
\hline $\begin{array}{l}\text { Capdevila et al. 2018, prospective } \\
\text { single-arm phase II study }\end{array}$ & $\begin{array}{l}\text { Spain, multicenter } \\
\text { study }\end{array}$ & 43 & $\begin{array}{l}\text { advanced nonfunctioning } \\
\text { well-differentiated GI-NETs }\end{array}$ & $\begin{array}{l}\text { Everolimus plus octreotide, } 28.9 \\
\text { months(median) }\end{array}$ & $\begin{array}{l}\text { PFS,OS,ORR,PR, } \\
\text { SD,PD,Safety }\end{array}$ \\
\hline $\begin{array}{l}\text { Comparative study }(n=4) \text {, Yao et al. } \\
\text { 2010,RADIANT-1,nonrandomized } \\
\text { open-label, phase II study }\end{array}$ & $\begin{array}{l}\text { International, } \\
\text { multicenter study }\end{array}$ & 160 & $\begin{array}{l}\text { Advanced pancreatic NETs } \\
\text { with progressive disease }\end{array}$ & $\begin{array}{l}\text { Everolimus plus octreotide }(n=45) \\
\text { vs. everolimus alone }(n=115)\end{array}$ & $\begin{array}{l}\text { PFS, OS, ORR, } \\
\text { SD, PD, Safety }\end{array}$ \\
\hline $\begin{array}{l}\text { Pavel et al.2011, } \\
\text { RADIANT-2,randomized double-blind } \\
\text { placebo-controlled phase III study }\end{array}$ & $\begin{array}{l}\text { International, } \\
\text { multicenter study }\end{array}$ & 429 & $\begin{array}{l}\text { Metastatic or unresectable } \\
\text { NETs }\end{array}$ & $\begin{array}{l}\text { Everolimus plus octreotide }(n= \\
216) \text { vs. octreotide alone }(n=213) \text {, } \\
37 \text { vs. } 36.6 \text { weeks(median) }\end{array}$ & $\begin{array}{l}\text { PFS, ORR, PR, } \\
\text { SD, PD, Safety }\end{array}$ \\
\hline $\begin{array}{l}\text { Kulke et al. 2017,COOPERATE-2, } \\
\text { randomized, open-label, phase II study }\end{array}$ & $\begin{array}{l}\text { International, } \\
\text { multicenter study }\end{array}$ & 160 & $\begin{array}{l}\text { Well-differentiated advanced } \\
\text { pancreatic NETs }\end{array}$ & $\begin{array}{l}\text { Everolimus plus pasireotide }(n= \\
79) \text { vs. everolimus alone }(n=81) \text {, } \\
49.4 \text { vs. } 48.3 \text { weeks (median) }\end{array}$ & $\begin{array}{l}\text { PFS, OS, ORR, } \\
\text { DCR, Safety }\end{array}$ \\
\hline $\begin{array}{l}\text { Ferolla et al. 2017, LUNA, randomized, } \\
\text { open-label, phase II study }\end{array}$ & $\begin{array}{l}\text { International, } \\
\text { multicenter study }\end{array}$ & 124 & $\begin{array}{l}\text { Advanced, } \\
\text { well-differentiated carcinoid } \\
\text { tumors of the lung or thymus }\end{array}$ & $\begin{array}{l}\text { Pasireotide alone }(n=41) \\
\text { everolimus alone }(n=42) \\
\text { pasireotide plus everolimus }(n= \\
41)\end{array}$ & $\begin{array}{l}\text { PFS, PR, SD, PD, } \\
\text { Safety }\end{array}$ \\
\hline
\end{tabular}

Table 2. Efficacy data reported in the included studies.

\begin{tabular}{|c|c|c|c|c|c|c|c|c|}
\hline \multirow[t]{2}{*}{ Study reference } & \multirow[t]{2}{*}{ Treatment } & \multicolumn{2}{|l|}{ Survival } & \multicolumn{5}{|c|}{ Tumor response } \\
\hline & & Median PFS & Median OS & CR & PR & SD & PD & CGA response \\
\hline \multirow[t]{2}{*}{ Yao et al. 2008} & Oct plus Eve $5 \mathrm{mg}$ & 50 (23-78), weeks & Not reached & NR & $13 \%$ & $73 \%$ & $13 \%$ & $70 \%(26 / 37)$ \\
\hline & Oct plus Eve $10 \mathrm{mg}$ & 72 (60-83), weeks & & NR & $30 \%$ & $67 \%$ & $3 \%$ & NR \\
\hline Bajetta et al. 2014 & Oct plus Eve & Not reached & Not reached & $2 \%$ & $16 \%$ & $74 \%$ & $6 \%$ & $58 \%(38$ in total $)$ \\
\hline Capdevila et al. 2015 & Lan or Oct plus Eve & 25.8 (11.3-40.3)months & 26.4 (17.5-35.4)months & 0 & $17.5 \%$ & $61.5 \%$ & $14 \%$ & $59 \%(16 / 27)$ \\
\hline Capdevila et al. 2018 & Oct plus Eve & 20.3(14.2-19.1)months & Not reached & NR & $2.3 \%$ & $58.1 \%$ & $39.6 \%$ & $13.6 \%(6 / 43)$ \\
\hline \multirow[t]{2}{*}{ Yao et al. 2010} & Oct plus Eve & 16.7 (8.3-13.3), months & Not reached & NR & $4.4 \%$ & $80 \%$ & 0 & $60 \%(15 / 25)$ \\
\hline & Eve alone & 9.7 (11.1-NA), months & 24.9 (20.2-27.1), months & NR & $9.6 \%$ & $67.8 \%$ & $13.9 \%$ & $50.7 \%(38 / 75)$ \\
\hline \multirow[t]{2}{*}{ Pavel et al. 2011} & Oct plus Eve & 16.4 (13.7-21.2), months & 29.2 (23.8-35.9), months & NR & $2 \%$ & $84 \%$ & $4 \%$ & $46 \%(75 / 164)$ \\
\hline & Oct plus placebo & 11.3 (8.4-14.6), months & 35.2 (30-44.7), months & NR & $2 \%$ & $81 \%$ & $12 \%$ & $36 \%(53 / 146)$ \\
\hline \multirow[t]{2}{*}{ Kulke et al. $2017^{*}$} & Pas plus Eve & 16.8 (12.1-19.6), months & Not reached & & $20.3 \%$ & $\mathrm{NE}$ & NR & NR \\
\hline & Eve alone & 16.6 (11.1-19.5), months & Not reached & & $6.2 \%$ & $\mathrm{NE}$ & NR & NR \\
\hline \multirow[t]{3}{*}{ Ferolla et al. 2017} & Pas & 8.5 (5.7-NE) months & Not reached & 0 & $2.4 \%$ & $34.1 \%$ & $17.1 \%$ & NR \\
\hline & Eve & 12.5 (5.6-NE) months & Not reached & 0 & $2.4 \%$ & $31 \%$ & $2.4 \%$ & NR \\
\hline & Pas plus Eve & 11.8 (11.1-NE) months & Not reached & 0 & $2.4 \%$ & 48.8 & 0 & NR \\
\hline
\end{tabular}

Oct: octreotide; Eve: everolimus; Lan: lanreotide; Pas: pasireotide; PFS: progression-free survival; OS: overall survival; CR: complete response; PR: partial response; SD: stable disease; PD: progressive disease; DCR: disease control rate; NA: not available; NE: not estimable; NR: not reported.

Chromogranin A (CGA) response: either normalization or > 50\% reduction (Yao et al. 2008) or a 25\% reduction in elevated CGA levels (Bajetta et al. 2014) ; early biochemical response: either normalization or more than $30 \%$ reduction at week 4 in CGA levels (Capdevila et al. 2018)

${ }^{*}$ Kulke et al. reported a DCR of $77.2 \%$ in the pasireotide plus everolimus subgroup and $82.7 \%$ in the single-arm everolimus subgroup.

Tumor response was evaluated according to the RECIST version 1.0, and PR, SD, and PD were reported in almost all of the studies. A CR rate of only $2 \%$ was reported in the study by Bajetta et al., while overall DCR rates of $82.7 \%$ and $77.2 \%$ in the everolimus single-arm and combination groups, respectively, were reported by Kulke et al. The ORRs ranged from 2\% (RADIANT-2) to 22\% (Yao et al. 2008 phase II study,) with no apparent differences between the combination and single-arm groups (either everolimus or SSA alone) in the limited results. The overall DCR rate was similar among the eight studies, ranging from 77.4 to $97 \%$. Everolimus, with or without SSAs, showed lower PD rates compared with SSAs alone ( $0 \%$ vs. $13.9 \%$, Yao et al. $2010 ; 4 \%$ vs. $12 \%$, Yao et al. $2011 ; 0 \%$ vs. $2.4 \%$ vs. $11.7 \%$, Ferolla et al.). Six of the eight studies reported that $13.6-70 \%$ of patients with elevated CGA levels experienced either normalization or a $>50 \%$ reduction (Yao et al. 2008) or a $25 \%$ reduction (Bajetta et al. 2014) or a $30 \%$ reduction (Capdevila et al. 2018) in CGA level. At present, the prognostic factors predicting the treatment response of NETs to targeted therapy and SSAs are under debate. The RADIANT-2 study 
showed that the baseline CGA level was not predictive of treatment response, whereas a low baseline CGA level was a good prognostic factor for OS regardless of the treatment type. According to the efficacy results, the addition of everolimus did slow down the growth of neuroendocrine tumors, but the long-term effect needs further investigation.

\section{Safety}

As shown in Table 3, the most common AEs were hematological abnormalities, including thrombocytopenia, leukopenia, and neutropenia; biochemical abnormalities, including hyperglycemia and hypertriglyceridemia; and non-hematological abnormalities, including stomatitis and mucositis, rash, diarrhea, fatigue, vomiting, and pneumonitis. The majority of AEs were mild and classified as grade 1-2 according to the Common Terminology Criteria for Adverse Events version 3.0. In the Yao et al. 2008 study, patients receiving $10 \mathrm{mg}$ everolimus daily in combination with SSAs seemed to suffer a higher percentage of AEs than did those receiving $5 \mathrm{mg}$ daily. Several studies have investigated the efficacy and safety of single-arm $10 \mathrm{mg}$ daily everolimus administration for the treatment of pancreatic, lung, and gastrointestinal NETs [16, 17], and patients commonly received $10 \mathrm{mg}$ everolimus daily in included studies, those suffered severe AEs followed dose reduction to continue studies. In contrast, in the studies we reviewed, patients treated with everolimus plus SSAs usually suffered higher AE rates than did those treated with everolimus alone (thrombocytopenia, 13.3 vs. $7.8 \%$; leukopenia, 13.3 vs. $7 \%$, Yao et al. 2010; hyperglycemia, 75.6 vs. $27.2 \%$, Kulke et al. 2017).

Generally, only a small proportion of patients discontinued the proposed treatment due to grade 3-4 AEs, whereas in the strict RADIANT-2 RCT, $83 \%$ and $84 \%$ of patients discontinued the proposed intervention in octreotide plus everolimus group and octreotide plus placebo group, respectively. It was meaningful that participants assigned to the placebo plus octreotide LAR group crossed over to the open-label everolimus plus octreotide LAR group after disease progression was observed. Under the uncertain effect of the addition of everolimus, especially for long-term survival and quality of life, more conditions should be taken into consideration and more specific studies are imperative.

\section{Discussion}

With a rapid increase in the number of patients diagnosed with NETs, more and more attention has been focused on NET research [1]. Because of their high level of heterogeneity and diverse biological characteristics, some NETs progress slowly and may be cured by surgical resection, whereas most show malignant behaviors of rapid progression and metastasis and are already too advanced for surgical treatment by the time of diagnosis [34, 35].

SSAs have been used to alleviate clinical symptoms caused by carcinoid tumors, and octreotide has subsequently been shown to inhibit tumor growth and exert long-lasting anti-proliferative effects in some gastroenteropancreatic NETs [36, 37]. Several phase II or III studies have demonstrated this antitumor effect of prolonged PFS for first-generation (octreotide and lanreotide) and second-generation (pasireotide) SSAs, which showed different affinities for different SSTR subtypes [8, 9, 28]. SSAs were really effective in symptom control for patients with relatively well or moderately differentiated NETs which might progress slowly in itself, for advanced NETs, it was far from enough. Because of the limited outcomes of cytotoxic chemotherapy drugs such as 5-fluorouracil, doxorubicin, capecitabine, and temozolomide, which showed relatively poor therapeutic effects and more toxic events, there's still a long way for traditional chemotherapy drugs to go [38-40]. Molecular targeted therapies, especially the mTOR inhibitor everolimus and tyrosine kinase inhibitor sunitinib, have been playing increasingly important roles in investigations of NETs [41, 42]; both everolimus and sunitinib have shown efficacy in prolonging PFS in patients with NETs. In fact, many patients discontinued their scheduled treatments due to serious AEs, and patients in the placebo groups who suffered disease progression crossed over to the treatment group, which might cause bias inevitably, whereas the roles of these treatments in OS are still under debate, and more studies focusing on their combination use with SSAs or traditional chemotherapy drugs are urgently needed.

Everolimus administered orally at $10 \mathrm{mg}$ daily has been deemed effective and tolerable in patients with advanced NETs. In related clinical trials, Yao et al. demonstrated that the addition of everolimus in combination with octreotide LAR was tolerable in patients with NETs [31]. The RADIANT-1 and RADIANT-2 trials prospectively demonstrated that patients administered everolimus in combination with SSAs had longer PFS compared with those given everolimus or an SSA alone. In contrast, to our surprise, the octreotide group exhibited a longer OS than that of the octreotide plus everolimus group [15], and subgroup analyses of lung and colorectal NETs in the RADIANT-2 study showed similar outcomes [43, 44]. Kulke et al. and Ferolla et al. did not report longer PFS, and OS has not yet been established in their patient cohorts $[27,28]$. There is debate over whether the addition of everolimus to octreotide LAR confers 
survival advantages over octreotide LAR or everolimus alone. In fact, the addition of everolimus may increase the incidence of serious AEs and tumor burden; i.e., not all patients with NETs, regardless of differentiation, may benefit from the combination of everolimus and SSAs. Identifying which patients are potential beneficial candidates of combined treatment requires further investigation [45]. Some patients followed chemotherapy, partial surgery or SSAs before they were enrolled into phase II or III study of everolimus [46, 47], which might also impact the effects of everolimus, therefore, more specific studies focusing on different prior treatment should be conducted even in rare patients of NETs, although it is difficult, it is also necessary. Furthermore, a phase II study of sunitinib treatment of metastatic renal cell carcinoma indicated the feasibility of extended treatment breaks, i.e., when patients achieved an SD status, treatment breaks helped reduce AEs, decrease costs, and even improve treatment outcomes [48]. In the treatment of NETs, whether it is cost-effective to interrupt everolimus or SSAs in SD status, and can everolimus reduce tumor burden and turn to surgery for patients who were previously unsuitable for surgery, all of which are uncertain and more studies investigating everolimus treatment of NETs are urgently needed to achieve a better understanding of everolimus and NETs.

Of the four comparative studies of SSAs plus everolimus versus everolimus alone treatments, no advantages in terms of ORR or DCR were observed in the combination treatment groups (everolimus plus SSAs group vs. everolimus alone group, ORR: 4.4 vs. $9.6 \%$, Yao et al. 2010; 20.3 vs. $6.2 \%$, Kulke et al. 2017; 2.4 vs. $2.4 \%$, Ferolla et al. 2017; DCR: 84.4 vs. $77.4 \%$, Yao et al. 2010; 77.2 vs. $82.7 \%$, Kulke et al. 2017; 51.2 vs. $33.4 \%$, Ferolla et al. 2017). Due to the limited comparative studies, and because it is unreasonable to compare combined treatment trials with other SSA or everolimus single-arm treatment trials across different studies, it remains unclear whether the addition of everolimus significantly inhibits tumor progression, even though SSAs or everolimus single-arm treatment showed significantly longer PFS and higher ORRs when compared with placebo treatment.

SSAs and everolimus commonly induce different AEs. SSAs have been used to ameliorate symptoms of flushing, diarrhea, abdominal pain, and heart valve disease in patients with carcinoid tumor $[49,50]$, and the main AEs of SSAs include hyperglycemia, fatigue, and nausea. Since everolimus use began in recent years [51], stomatitis, mucositis, rash, diarrhea, fatigue, and hyperglycemia have been the most commonly reported AEs. Recent studies indicated that concomitant everolimus administration may increase the minimum concentration of octreotide [52], whether the combination increases the incidence of AEs and impairs health-related quality of life remains unknown. As described above, patients treated with everolimus plus SSAs usually suffered higher rates of certain AEs such as thrombocytopenia, leukopenia, and hyperglycemia than did those treated with everolimus alone, whereas the incidences of other AEs were similar, hence the AE grade of 3-4. In the RADIANT-2 trial, most patients discontinued the intervention because of disease progression rather than serious AEs, and some patients who suffered serious AEs continued treatment after a dose reduction or suspension. Generally, treatment with 10 $\mathrm{mg}$ daily everolimus orally in combination with SSAs LAR is safe for most patients. Although the addition of everolimus showed better anti-tumor effects, it might not be worthwhile to suffer more adverse events in exchange for unpredictable survival time, and the quality of life cannot be ignored.

Table 3. Safety data reported in the included studies. Adverse events, (AEs), all grades (grades 3-4), percent.

\begin{tabular}{|c|c|c|c|c|c|c|c|c|c|c|}
\hline \multirow[t]{2}{*}{ Study reference } & \multirow[t]{2}{*}{ Treatment } & \multirow{2}{*}{$\begin{array}{l}\text { Discontin } \\
\text { uation }\end{array}$} & \multicolumn{2}{|c|}{ Hematologic AEs } & \multicolumn{2}{|c|}{ Biochemical abnormality } & \multicolumn{4}{|c|}{ Non-hematologic AEs } \\
\hline & & & $\begin{array}{l}\text { Thrombocy } \\
\text { topenia }\end{array}$ & $\begin{array}{l}\text { Leukopenia/ } \\
\text { neutropenia }\end{array}$ & $\begin{array}{l}\text { Hyperglyce } \\
\text { mia }\end{array}$ & $\begin{array}{l}\text { Hypophosp } \\
\text { hatemia }\end{array}$ & $\begin{array}{l}\text { Stomatitis/ } \\
\text { mucositis }\end{array}$ & Rash & Fatigue & Diarrhea \\
\hline \multirow[t]{2}{*}{ Yao et al.2008* } & Oct, Eve $5 \mathrm{mg}$ & $5 \%$ & 3 & 3 & 3 & 6 & 6 & 6 & 15 & 9 \\
\hline & Oct, Eve $10 \mathrm{mg}$ & & 6 & 6 & 16 & 16 & 9 & 3 & 6 & 13 \\
\hline Bajetta et al. 2014 & Oct plus Eve, $10 \mathrm{mg}$ & $6 \%$ & 12 & $6(2)$ & 18 & NR & $62(10)$ & $48(2)$ & NR & $60(22)$ \\
\hline Capdevila et al. 2015 & Lan plus Eve, $10 \mathrm{mg}$ & NE & 0 & 0 & $7(2)$ & 0 & 0 & $2(2)$ & NR & 2 \\
\hline Capdevila et al. 2018 & Oct plus Eve & NR & NR & NR & $15.9(4.5)$ & NR & $65.9(2.3)$ & 15 & $61.4(9.1)$ & $70.5(6.8)$ \\
\hline \multirow[t]{2}{*}{ Yao et al. 2010} & Oct plus Eve & NR & $13.3(8.9)$ & 13.3 & $13.3(4.4)$ & NR & $48.9(2.2)$ & 44.4 & $35.6(2.2)$ & 31.1 \\
\hline & Eve alone & NR & $7.8(2.6)$ & $7.0(4.3)$ & $13(4.3)$ & NR & $45.2(4.3)$ & $40(0.9)$ & $31.3(4.3)$ & $39.1(3.5)$ \\
\hline \multirow[t]{2}{*}{ Pavel et al. 2011} & Oct plus Eve & $83 \%$ & $14(5)$ & NR & $12(5)$ & NR & $62(7)$ & $37(1)$ & $31(7)$ & $27(6)$ \\
\hline & Oct plus placebo & $84 \%$ & 0 & NR & $2(0.5)$ & NR & 14 & 12 & $23(3)$ & $16(2)$ \\
\hline \multirow[t]{2}{*}{ Kulke et al. 2017} & Pas plus Eve & NR & NR & NR & $75.6(37.2)$ & NR & $59(9)$ & NR & NR & $62.8(5.1)$ \\
\hline & Eve alone & NR & NR & NR & $27.2(11.1)$ & NR & $63(8.6)$ & NR & NR & $53.1(3.7)$ \\
\hline \multirow[t]{3}{*}{ Ferolla et al. 2017} & Pas & $20(48.8 \%)$ & 0 & NR & $51(7)$ & 2 & 5 & 2 & $17(2)$ & $48(9)$ \\
\hline & Eve & $24(57.1 \%)$ & $23(2)$ & NR & $46(17)$ & $10(5)$ & $79(12)$ & $33(7)$ & $19(2)$ & $50(7)$ \\
\hline & Pas plus Eve & $16(39.0 \%)$ & 17 & NR & NR & $14(2)$ & $51(7)$ & 12 & $34(10)$ & 95 (19) \\
\hline
\end{tabular}

*Yao et al. 2008 study: only grade 3-4 AEs were present. Oct: octreotide; Eve: everolimus; Lan: lanreotide; Pas: pasireotide; NR: not reported; NE: not estimable. 
Recent studies have reported that circulating biomarkers, such as 5-HIAA, NSE, and CGA, have the potential to predict disease prognosis and evaluate treatment outcomes [53, 54]. In the studies we evaluated, CGA was the most commonly used biomarker to predict treatment response. CGA levels showed an obvious decrease, ranging from $46-70 \%$ in the everolimus plus SSA groups, higher than those in the single-arm groups. Yao et al. showed a better PFS in patients with a greater response of CGA than in those with a poor response [29]. Other markers such as tumor tissue markers and imaging markers are also emerging as evaluation factors for predicting treatment response[55,56], however, due to the not that satisfied sensitivity and specificity, it is still a long way for its widely application in clinical treatment, and more convincing evidence is needed.

Due to the great heterogeneity among NETs, it is difficult to recruit patients with NETs of similar characteristics in current clinical trials; thus, certain biases are inevitable. In this review, there were some limitations, such as in some studies, patients received another treatment prior to SSAs plus everolimus, the proportion of patients with disease progression differed among the studies, and no quantitative analyses were conducted. However, we indicate that everolimus in combination with SSAs for NET treatment showed considerable positive outcomes, with discussion of the unknown areas that require further investigation. In the future, more specific clinical trials should be conducted, by applying stricter inclusion criteria, performing subgroup analyses according to origin (e.g., lung, thymus, small intestine, pancreas, and colon/rectum) to reduce heterogeneity, and considering prior treatment before inclusion.

In conclusion, everolimus plus SSAs treatment of NETs showed favorable outcomes, while its role in the prolong of overall survival is still uncertain, whether patients benefit from the addition of everolimus to SSAs requires further investigation, and studies aiming to reduce heterogeneity among patients should be conducted to provide more convincing evidence.

\section{Abbreviations}

mTOR: mammalian target of rapamycin; SSAs: Somatostatin analogues; RCTs: randomized controlled trials; NETs: Neuroendocrine tumors; SSTR: somatostatin receptor; PFS: progression-free survival; OS: overall survival; AE: adverse events.

\section{Acknowledgments}

This study was supported by the National Natural Science Foundation of China (NSFC-81572307 and NSFC-81773096), Major Project of Medical and Health Technology Development Program in Zhejiang Province(WKJ-ZJ-1702) and the Major Program of Science and Technology of Zhejiang Province (No. 2014C13G2010059).

\section{Competing Interests}

The authors have declared that no competing interest exists.

\section{References}

1. Dasari A, Shen C, Halperin D, Zhao B, Zhou S, Xu Y, et al. Trends in the Incidence, Prevalence, and Survival Outcomes in Patients With Neuroendocrine Tumors in the United States. JAMA oncology. 2017; 3: 1335-42.

2. Hallet J, Law CH, Cukier M, Saskin R, Liu N, Singh S. Exploring the rising incidence of neuroendocrine tumors: a population-based analysis of epidemiology, metastatic presentation, and outcomes. Cancer. 2015; 121: 589-97.

3. Lamberts SW, van der Lely AJ, de Herder WW, Hofland LJ. Octreotide. The New England journal of medicine. 1996; 334: 246-54.

4. Reubi JC, Laissue J, Krenning E, Lamberts SW. Somatostatin receptors in human cancer: incidence, characteristics, functional correlates and clinical implications. J Steroid Biochem Mol Biol. 1992; 43: 27-35.

5. Kumar U, Sasi R, Suresh S, Patel A, Thangaraju M, Metrakos P, et al. Subtype-selective expression of the five somatostatin receptors (hSSTR1-5) in human pancreatic islet cells: a quantitative double-label immunohistochemical analysis. Diabetes. 1999; 48: 77-85.

6. de Herder WW, Hofland LJ, van der Lely AJ, Lamberts SW. Somatostatin receptors in gastroentero-pancreatic neuroendocrine tumours. Endocrine-related cancer. 2003; 10: 451-8.

7. Thulin L, Samnegard H, Tyden G, Long DH, Efendic S. Efficacy of somatostatin in a patient with carcinoid syndrome. Lancet (London, England). 1978; $2: 43$.

8. Caplin ME, Pavel M, Ruszniewski P. Lanreotide in metastatic enteropancreatic neuroendocrine tumors. The New England journal of medicine. 2014; 371: 1556-7.

9. Rinke A, Muller HH, Schade-Brittinger C, Klose KJ, Barth P, Wied M, et al. Placebo-controlled, double-blind, prospective, randomized study on the effect of octreotide LAR in the control of tumor growth in patients with metastatic neuroendocrine midgut tumors: a report from the PROMID Study Group. Journal of clinical oncology : official journal of the American Society of Clinical Oncology. 2009; 27: 4656-63.

10. Rinke A, Wittenberg M, Schade-Brittinger C, Aminossadati B, Ronicke E, Gress TM, et al. Placebo-Controlled, Double-Blind, Prospective, Randomized Study on the Effect of Octreotide LAR in the Control of Tumor Growth in Patients with Metastatic Neuroendocrine Midgut Tumors (PROMID): Results of Long-Term Survival. Neuroendocrinology. 2017; 104: 26-32.

11. De Wilde RF, Edil BH, Hruban RH, Maitra A. Well-differentiated pancreatic neuroendocrine tumors: From genetics to therapy. Nature Reviews Gastroenterology and Hepatology. 2012; 9: 199-208.

12. Cella CA, Minucci S, Spada F, Galdy S, Elgendy M, Ravenda PS, et al. Dual inhibition of mTOR pathway and VEGF signalling in neuroendocrine neoplasms: From bench to bedside. Cancer Treatment Reviews. 2015; 41: 754-60.

13. Scarpa A, Chang DK, Nones K, Corbo V, Patch AM, Bailey P, et al. Whole-genome landscape of pancreatic neuroendocrine tumours. Nature. 2017; 543: 65-71.

14. Bjornsti MA, Houghton PJ. The TOR pathway: a target for cancer therapy. Nature reviews Cancer. 2004; 4: 335-48.

15. Pavel ME, Hainsworth JD, Baudin E, Peeters M, Horsch D, Winkler RE, et al. Everolimus plus octreotide long-acting repeatable for the treatment of advanced neuroendocrine tumours associated with carcinoid syndrome (RADIANT-2): a randomised, placebo-controlled, phase 3 study. Lancet (London, England). 2011; 378: 2005-12.

16. Yao JC, Shah MH, Ito T, Bohas CL, Wolin EM, Van Cutsem E, et al. Everolimus for advanced pancreatic neuroendocrine tumors. The New England journal of medicine. 2011; 364: 514-23.

17. Yao JC, Fazio N, Singh S, Buzzoni R, Carnaghi C, Wolin E, et al. Everolimus for the treatment of advanced, non-functional neuroendocrine tumours of the lung or gastrointestinal tract (RADIANT-4): a randomised, placebo-controlled, phase 3 study. Lancet (London, England). 2016; 387: 968-77.

18. Fazio N, Cinieri S, Lorizzo K, Squadroni M, Orlando L, Spada F, et al. Biological targeted therapies in patients with advanced enteropancreatic neuroendocrine carcinomas. Cancer treatment reviews. 2010; 36 Suppl 3: S87-94.

19. Lee A, Chan DL, Wong MH, Li BT, Lumba S, Clarke SJ, et al. Systematic Review of the Role of Targeted Therapy in Metastatic Neuroendocrine Tumors. Neuroendocrinology. 2017; 104: 209-22. 
20. Berruti A, Fazio N, Ferrero A, Brizzi MP, Volante M, Nobili E, et al Bevacizumab plus octreotide and metronomic capecitabine in patients with metastatic well-to-moderately differentiated neuroendocrine tumors: the XELBEVOCT study. BMC cancer. 2014; 14: 184

21. Phan AT, Halperin DM, Chan JA, Fogelman DR, Hess KR, Malinowski P, et al. Pazopanib and depot octreotide in advanced, well-differentiated neuroendocrine tumours: a multicentre, single-group, phase 2 study. The Lancet Oncology. 2015; 16: 695-703.

22. Yao JC, Guthrie KA, Moran C, Strosberg JR, Kulke MH, Chan JA, et al. Phase III Prospective Randomized Comparison Trial of Depot Octreotide Plus Interferon Alfa-2b Versus Depot Octreotide Plus Bevacizumab in Patients With Advanced Carcinoid Tumors: SWOG S0518. Journal of clinical oncology : official journal of the American Society of Clinical Oncology. 2017; 35: 1695-703.

23. Therasse P, Arbuck SG, Eisenhauer EA, Wanders J, Kaplan RS, Rubinstein L, et al. New guidelines to evaluate the response to treatment in solid tumors. European Organization for Research and Treatment of Cancer, National Cancer Institute of the United States, National Cancer Institute of Canada. Journal of the National Cancer Institute. 2000; 92: 205-16.

24. Higgins JPT GSe. Cochrane Handbook for Systematic Reviews of Interventions Version 5.1.0 [updated March 2011]. The Cochrane Collaboration. 2011; Available from www.handbook.cochrane.org.

25. Wells G, Shea B, O'Connell D, Peterson j, Welch V, Losos M, et al. The Newcastle-Ottawa Scale (NOS) for Assessing the Quality of Non-Randomized Studies in Meta-Analysis; 2000

26. Pavel ME, Baudin E, Oberg KE, Hainsworth JD, Voi M, Rouyrre N, et al. Efficacy of everolimus plus octreotide LAR in patients with advanced neuroendocrine tumor and carcinoid syndrome: final overall survival from the randomized, placebo-controlled phase 3 RADIANT-2 study. Annals of oncology. Official journal of the European Society for Medical Oncology. 2017; 28: 1569-75

27. Kulke MH, Ruszniewski P, Van Cutsem E, Lombard-Bohas C, Valle JW, De Herder WW, et al. A randomized, open-label, phase 2 study of everolimus in combination with pasireotide LAR or everolimus alone in advanced, well-differentiated, progressive pancreatic neuroendocrine tumors: COOPERATE-2 trial. Annals of Oncology. 2017; 28: 1309-15

28. Ferolla P, Brizzi MP, Meyer T, Mansoor W, Mazieres J, Do Cao C, et al. Efficacy and safety of long-acting pasireotide or everolimus alone or in combination in patients with advanced carcinoids of the lung and thymus (LUNA): an open-label, multicentre, randomised, phase 2 trial. The Lancet Oncology. 2017; 18: 1652-64

29. Yao JC, Lombard-Bohas C, Baudin E, Kvols LK, Rougier P, Ruszniewski P, et al. Daily oral everolimus activity in patients with metastatic pancreatic neuroendocrine tumors after failure of cytotoxic chemotherapy: a phase II trial. Journal of clinical oncology : official journal of the American Society of Clinical Oncology. 2010; 28: 69-76.

30. Bajetta E, Catena L, Fazio N, Pusceddu S, Biondani P, Blanco G, et al. Everolimus in combination with octreotide long-acting repeatable in a first-line setting for patients with neuroendocrine tumors: an ITMO group study. Cancer. 2014; 120: 2457-63.

31. Yao JC, Phan AT, Chang DZ, Wolff RA, Hess K, Gupta S, et al. Efficacy of RAD001 (everolimus) and octreotide LAR in advanced low- to intermediate-grade neuroendocrine tumors: results of a phase II study. Journal of clinical oncology : official journal of the American Society of Clinical Oncology. 2008; 26: 4311-8.

32. Capdevila J, Teule A, Barriuso J, Castellano D, Lopez C, Manzano JL, et al. Phase II Study of Everolimus and Octreotide LAR in Patients with Nonfunctioning Gastrointestinal Neuroendocrine Tumors: The GETNE1003_EVERLAR study. The oncologist. 2018.

33. Capdevila J, Sevilla I, Alonso V, Anton Aparicio L, Jimenez Fonseca P, Grande E, et al. Evaluation of the efficacy and safety of lanreotide in combination with targeted therapies in patients with neuroendocrine tumours in clinical practice: a retrospective cross-sectional analysis. BMC cancer. 2015; 15: 495

34. Singh S, Asa SL, Dey C, Kennecke H, Laidley D, Law C, et al. Diagnosis and management of gastrointestinal neuroendocrine tumors: An evidence-based Canadian consensus. Cancer Treatment Reviews. 2016; 47: 32-45.

35. Fairweather M, Swanson R, Wang J, Brais LK, Dutton T, Kulke MH, et al. Management of Neuroendocrine Tumor Liver Metastases: Long-Term Outcomes and Prognostic Factors from a Large Prospective Database. Annals of Surgical Oncology. 2017; 24: 2319-25.

36. Arnold R, Trautmann ME, Creutzfeldt W, Benning R, Benning M, Neuhaus C, et al. Somatostatin analogue octreotide and inhibition of tumour growth in metastatic endocrine gastroenteropancreatic tumours. Gut. 1996; 38: 430-8.

37. Enzler T, Fojo T. Long-acting somatostatin analogues in the treatment of unresectable/metastatic neuroendocrine tumors. Seminars in oncology. 2017; 44: $141-56$

38. Moertel CG, Lefkopoulo M, Lipsitz S, Hahn RG, Klaassen D. Streptozocin-doxorubicin, streptozocin-fluorouracil or chlorozotocin in the treatment of advanced islet-cell carcinoma. The New England journal of medicine. 1992; 326: 519-23.

39. Koumarianou A, Kaltsas G, Kulke MH, Oberg K, Strosberg JR, Spada F, et al. Temozolomide in Advanced Neuroendocrine Neoplasms: Pharmacological and Clinical Aspects. Neuroendocrinology. 2015; 101: 274-88.

40. McAuliffe JC, Wolin EM. Randomized Controlled Trials in Neuroendocrine Tumors. Surgical Oncology Clinics of North America. 2017; 26: 751-65.
41. Raymond E, Dahan L, Raoul JL, Bang YJ, Borbath I, Lombard-Bohas C, et al. Sunitinib malate for the treatment of pancreatic neuroendocrine tumors. The New England journal of medicine. 2011; 364: 501-13.

42. Faivre S, Niccoli P, Castellano D, Valle JW, Hammel P, Raoul JL, et al. Sunitinib in pancreatic neuroendocrine tumors: updated progression-free survival and final overall survival from a phase III randomized study. Annals of oncology : official journal of the European Society for Medical Oncology. 2017; 28: 339-43.

43. Castellano D, Bajetta E, Panneerselvam A, Saletan S, Kocha W, O'Dorisio T, et al. Everolimus plus octreotide long-acting repeatable in patients with colorectal neuroendocrine tumors: a subgroup analysis of the phase III RADIANT-2 study. The oncologist. 2013; 18: 46-53.

44. Fazio N, Granberg D, Grossman A, Saletan S, Klimovsky J, Panneerselvam A, et al. Everolimus plus octreotide long-acting repeatable in patients with advanced lung neuroendocrine tumors: analysis of the phase 3, randomized, placebo-controlled RADIANT-2 study. Chest. 2013; 143: 955-62.

45. Berdelou A, Boige V, Arfi-Rouche J, Malka D, Ederhy S, Izzedine H, et al. Not All Patients with a Pancreatic Neuroendocrine Tumour Will Benefit from All Approved or Recommended Therapeutic Options: A Real-Life Retrospective Study. Neuroendocrinology. 2017; 105: 26-34.

46. Lombard-Bohas C, Yao JC, Hobday T, Van Cutsem E, Wolin EM, Panneerselvam A, et al. Impact of prior chemotherapy use on the efficacy of everolimus in patients with advanced pancreatic neuroendocrine tumors: a subgroup analysis of the phase III RADIANT-3 trial. Pancreas. 2015; 44: 181-9.

47. Buzzoni R, Fave GD, Strosberg J, Voi M, Ridolfi A, Bubuteishvili-Pacaud L, et al. Impact of prior therapies on everolimus treatment in the subgroup of patients with advanced lung neuroendocrine tumors (NET) in the RADIANT-4 trial. Annals of Oncology. 2016; 27.

48. Ornstein MC, Wood LS, Elson P, Allman KD, Beach J, Martin A, et al. A Phase II Study of Intermittent Sunitinib in Previously Untreated Patients With Metastatic Renal Cell Carcinoma. Journal of clinical oncology : official journal of the American Society of Clinical Oncology. 2017; 35: 1764-9.

49. Wymenga AN, Eriksson B, Salmela PI, Jacobsen MB, Van Cutsem EJ, Fiasse $\mathrm{RH}$, et al. Efficacy and safety of prolonged-release lanreotide in patients with gastrointestinal neuroendocrine tumors and hormone-related symptoms. Journal of clinical oncology : official journal of the American Society of Clinical Oncology. 1999; 17: 1111.

50. Wolin EM, Jarzab B, Eriksson B, Walter T, Toumpanakis C, Morse MA, et al. Phase III study of pasireotide long-acting release in patients with metastatic neuroendocrine tumors and carcinoid symptoms refractory to available somatostatin analogues. Drug design, development and therapy. 2015; 9: $5075-86$

51. Yao JC, Lombard-Bohas C, Baudin E, Kvols LK, Rougier P, Ruszniewski P, et al. A phase II trial of daily oral RAD001 (EVEROLIMUS) in patients with metastatic pancreatic neuroendocrine tumors (NET) after failure of cytotoxic chemotherapy. Annals of Oncology. 2008; 19: viii167.

52. Pavel ME, Becerra C, Grosch K, Cheung W, Hasskarl J, Yao JC. Effect of everolimus on the pharmacokinetics of octreotide long-acting repeatable in patients with advanced neuroendocrine tumors: An analysis of the randomized phase III RADIANT-2 trial. Clinical pharmacology and therapeutics. 2017; 101: 462-8.

53. Yao JC, Pavel $M$, Phan AT, Kulke MH, Hoosen S, St Peter J, et al Chromogranin A and neuron-specific enolase as prognostic markers in patients with advanced pNET treated with everolimus. Journal of Clinical Endocrinology and Metabolism. 2011; 96: 3741-9.

54. Benslama N, Bollard J, Vercherat C, Massoma P, Roche C, Hervieu V, et al. Prediction of response to everolimus in neuroendocrine tumors: evaluation of clinical, biological and histological factors. Investigational new drugs. 2016; 34 : $654-62$

55. Meric-Bernstam F, Akcakanat A, Chen H, Do KA, Sangai T, Adkins F, et al. PIK3CA/PTEN mutations and Akt activation as markers of sensitivity to allosteric mTOR inhibitors. Clinical cancer research : an official journal of the American Association for Cancer Research. 2012; 18: 1777-89.

56. van Asselt SJ, Oosting SF, Brouwers AH, Bongaerts AH, de Jong JR, Lub-de Hooge MN, et al. Everolimus Reduces (89)Zr-Bevacizumab Tumor Uptake in Patients with Neuroendocrine Tumors. Journal of nuclear medicine : official publication, Society of Nuclear Medicine. 2014; 55: 1087-92. 